\title{
The time course of preview search with color-defined, not luminance-defined, stimuli
}

\author{
GLYN W. HUMPHREYS \\ University of Birmingham, Birmingham, England \\ CHRISTIAN N. L. OLIVERS \\ Vrije Universiteit, Amsterdam, The Netherlands \\ and \\ JASON J. BRAITHWAITE \\ University of Birmingham, Birmingham, England
}

\begin{abstract}
We examined the time course of preview search, using stimuli that were defined by color, but not by luminance changes. We demonstrate that, under these conditions, search performance in a preview condition improved selectively over time, relative to a baseline condition in which all the items appeared together. The data confirm earlier reports from Humphreys, Kyllinsbæk, et al. (2004) and Watson and Humphreys (1997), who used luminance-defined stimuli and showed a long time course to preview search. The data contradict Donk and Verburg (2004), who argued that the preview benefit was instantaneous but did not include baseline conditions with which to test for any influence of distractors equivalent to the old items in preview search, even under nonpreview conditions. The data support the proposal that the prioritization of new items in preview search is a time-consuming business.
\end{abstract}

Visual search benefits when a subset of the distractors is presented as a preview prior to the full search display (Watson, Humphreys, \& Olivers, 2003). Since the first demonstration of this preview benefit by Watson and Humphreys (1997), there has been considerable argument about the contributing processes. Watson and Humphreys originally argued that the benefit, at least in part, is based on inhibitory filtering of the old distractors, a process they termed visual marking. Opposing views have been put forward by Donk and Theeuwes (2001) and Jiang, Chun, and Marks (2002). Donk and Theeuwes proposed that the preview benefit was due solely to attentional capture by the new luminance onsets that characterized the arrival of the search items in the original experiments. Jiang et al. argued that the preview benefit was dependent only on temporal grouping and segmentation of the old and new sets; providing that the old and new items could be temporally segmented, the new search display could be selected without any influence of the old group.

\section{The Time Course of Preview Search}

One piece of evidence that distinguishes between the different accounts of preview search is the time course of the effect. Watson and Humphreys (1997; see also Humphreys, Kyllinsbæk, et al., 2004) reported that the preview

This work was supported by a grant from the MRC (U.K.). Correspondence concerning this article should be addressed to G. W. Humphreys, Behavioural Brain Sciences, School of Psychology, University of Birmingham, Birmingham B15 2TT, England (e-mail: g.w.humphreys@ bham.ac.uk). had to appear $500 \mathrm{msec}$ or so before the search display in order to generate an optimal search benefit. This is difficult to reconcile with either the luminance onset capture account or the temporal segmentation account, given that temporal segmentation between visual displays can be established with intervals as short as $100 \mathrm{msec}$ (Yantis \& Gibson, 1994). The data are, however, consistent with a slow process of inhibitory filtering. Humphreys, Watson, and Jolicœur (2002) further proposed that part of this interval was needed to encode a representation of the old items, as well as to deprioritize this representation before the new items appear.

More recently, though, Donk and Verburg (2004) have argued that the long time course to the preview benefit was caused by the old items' appearing as luminance onsets. They suggested that attention may be captured by the luminance onsets of the first items and that an interval is then needed in order to release attention so that it can be captured again by the search display. In support of their argument, Donk and Verburg presented old distractors that were isoluminant with the background. New items were defined by luminance onsets but then decreased in luminance back to the background. Donk and Verburg found that even when the old items appeared just $50 \mathrm{msec}$ prior to the new items, there was minimal impact of the old items on search. They argued from this that the preview benefit was instantaneous, suggesting also that the result was incompatible with visual marking (slow inhibition of the old items) and temporal segmentation (which may require intervals greater than $50 \mathrm{msec}$ between the displays; Yantis \& Gibson, 1994). In this article, we will examine these claims. 
In Donk and Verburg (2004), the old items were isoluminant with the background, and the new items appeared as luminance onsets that were brighter than the background. One issue here, though, is that isoluminant items may not compete strongly with brighter, nonisoluminant items, irrespective of the temporal intervals between the stimuli. For example, let us imagine that there is no impact of isoluminant distractors when participants search for a brighter, nonisoluminant target, even when all the stimuli appear simultaneously. If this is the case, the fact that the isoluminant items also have no impact when they precede the nonisoluminant search displays by $50 \mathrm{msec}$ (as in Donk \& Verburg, 2004) would not be surprising. Importantly, though, this would not represent a preview benefit, because the isoluminant distractors have no impact in any case. Donk and Verburg did not test for this, because they did not include a full-set baseline in their study, in which both the isoluminant and the nonisoluminant items appeared together; hence, they did not demonstrate a preview benefit.

We (Braithwaite, Humphreys, Watson, \& Hulleman, 2005) have examined this issue by comparing preview search with isoluminant old distractors and nonisoluminant (brighter) search items, relative to a full-set baseline for which the target and half the distractors were nonisoluminant but the remaining distractors were isoluminant (equivalent to the old items in preview search). We found that there was no benefit for search rates in the preview condition, in comparison with this full-set baseline. That is, the isoluminant distractors had minimal impact on search even when they appeared simultaneously with the nonisoluminant items. We conclude that it is premature to make conclusions about the time course of the preview benefit from conditions in which there is no preview benefit in the first place.

In the present study, we revisited the time course of the preview benefit, using conditions in which the search items were defined by color, but not by luminance. Under these conditions, and unlike in Donk and Verburg (2004), there was not a covarying factor (brightness relative to the background) that conveyed an inherent advantage for the new over the old items irrespective of their temporal relations, and we demonstrated that there is a benefit for preview search over a full-set baseline. We also showed that there is a prolonged time course to the preview benefit under these conditions.

\section{The Present Study}

To have search items defined by color, but not by luminance, we used displays introduced into preview search by Humphreys, Jung-Stalmann, and Olivers (2004; see Cepeda, Cave, Bichot, \& Kim, 1998, for an earlier application in visual search). At the start of a trial, the participants initially saw a blue grid that was not isoluminant with the background. Subsequently, shape stimuli were presented by changing the colors of the contours on the grid to form green or red shapes. The blue, red, and green colors were, on average, isoluminant with one another, and any differences were further masked by the addition of random luminance noise (produced by small random increments or decrements to the luminance levels of the segments making up the squares on the grid; see the Method section below). The grid was useful here because it meant that the shapes were not isoluminant with respect to the general screen background but the search items were, on average, isoluminant with the blue segments making up the grid. Hence, the shapes were clearly defined by their luminance, relative to the background screen, but the search items were defined by color, rather than by luminance, when they appeared on the grid. Furthermore, having the grid present in full-set and half-set baseline conditions, as well as in the preview, meant that any capture of attention by the luminance changes, before the first display, was present in the baselines, as well as in the preview condition. There should be no differential capture in the preview condition, and hence, if capture were the critical factor, the preview condition should not selectively improve as the interval between the initial grid and the search display increased. In Experiment 1, preview search was compared with a full-set baseline. In this baseline, the target was a red vertical rectangle, and the distractors were red horizontal rectangles and green vertical rectangles (i.e., the target was a color-form conjunction). In the preview condition, the green vertical distractors appeared first, followed by the red stimuli (the distractors plus the target, when present). There were three preview durations $(200,500$, and $1,000 \mathrm{msec})$, and two fixation durations were used in the full-set baseline (200 and 1,000 msec), in order to equate for effects of temporal expectation across the conditions. We assessed whether there was a selective benefit for the preview condition as the preview duration increased. In Experiment 2, we employed a form conjunction task in which the target was an inverted $\mathrm{T}$ and the distractors were upright $\mathrm{Ts}$ and Ts rotated $90^{\circ}$ to the right (cf. Humphreys, Quinlan, $\&$ Riddoch, 1989). The preview durations were 200 and $1,000 \mathrm{msec}$, and this was matched by equivalent fixation intervals in a full-set baseline. In Experiment 2, we tested whether any effect of time in the color-form conjunction condition was due to the color difference between the old and the new items in the preview version of the task. It is possible that, when the old and the new items segment by color, as well as by time, performance is influenced by color-based grouping and inhibition of color maps corresponding to the old color group (for evidence, see Agter \& Donk, 2005; Braithwaite \& Humphreys, 2003; Olivers $\&$ Humphreys, 2003). These processes of grouping and color-based inhibition could be time consuming and could generate a long time course for the preview benefit (or at least, an increasing preview benefit over time). They may not have affected performance in Donk and Verburg (2004) because a form conjunction task was employed (target $=\mathrm{H}$, distractors $=$ other random letters). If this holds, we should not see an increasing preview benefit across time in Experiment 2 here.

We also note that our assessment of a preview benefit when stimuli are defined by color, but not by luminance, is of interest in its own right, since any benefit under those conditions is not predicted by the luminance onset capture 
account. In the General Discussion section, we will return to consider this issue in more detail, reviewing both the present and previous evidence on preview search when stimuli are not defined by luminance onsets.

\section{EXPERIMENT 1 Time Course of Preview Search With Color-Form Stimuli}

\section{Method}

Participants. There were 13 participants ( 8 of them female, 5 male; age range, 18-29 years), all with either normal or correctedto-normal vision.

Stimuli. The stimuli were generated and presented on an IBMcompatible Pentium PC with a super VGA card and monitor. The displays were generated by programs written in Turbo Pascal. The computer recorded all the relevant mouse clicks and response times (RTs). The participants were seated approximately $50 \mathrm{~cm}$ from the screen, and the experiment was conducted under light-dimmed conditions.

The fixation cross was $0.45^{\circ} \times 0.45^{\circ}$ and was defined by white contours against a blue background grid $(22 \times 22$ squares $)$, which appeared against a black background. The grid measured $9.3^{\circ} \times 9.3^{\circ}$ (each rectangle covered an area of $1 \times 3$ squares of the grid, making them $0.42^{\circ} \times 1.27^{\circ}$ in size). Target and distractor rectangles for the search task were positioned randomly on the grid, with the proviso that they fell at least $1.27^{\circ}$ apart. The old items were green vertical rectangles, the new distractors were red horizontal rectangles, and the target was a red vertical rectangle. The term segment will be used to describe the contour along one side of each of the squares making up the grid (i.e., there were four segments per square). The colors were made to shimmer by randomly changing the RGB values for each segment in the grid between $-12 \%$ and $+12 \%$ (step size,
$1 \%$ ) every $16 \mathrm{msec}$. The blue, red, and green colors were tuned to be isoluminant for each participant- using a flicker fusion procedure, in which the red and green colors were, in turn, matched to a blue background - at three levels of luminance $(-12 \%$, mean, and $+12 \%)$. This was done to ensure that the colors remained isoluminant not only when set to their mean RGB value, but also when the maximal shimmer values were reached. Since the segments making up each search shape changed their luminance values randomly, the whole shape was not defined by a consistent luminance value, and the same luminance variation was also present on the background grid. This means that luminance could not be used as a search cue but, rather, search stimuli were defined by their colors (see also Snowden, 2002).

Design and Procedure. There were five search conditions, presented in separate blocks: two full-set (color-form conjunction) searches and three preview conditions. In all the conditions, each trial began with a fixation cross for $1,000 \mathrm{msec}$. The two conjunction conditions were identical, except that the fixation cross continued for different durations following its initial presentation; in one case, it was $200 \mathrm{msec}$, and in the other, it was $1,000 \mathrm{msec}$. The random luminance changes were carried out throughout this time. The minimum and maximum durations used for previews were then matched to those in the baseline conditions. In the three preview conditions, three different preview durations were used: 200, 500, and $1,000 \mathrm{msec}$. In each condition, there were two display sizes, with 6 and 14 items in the conjunction conditions $(3+3$ and $7+7$ items in the preview conditions).

The participants carried out one block of trials in each condition, in a single session lasting about $50 \mathrm{~min}$. The order of the conditions was randomized for each participant. Each block contained 120 trials, 60 with the target present and 60 with it absent, 30 trials at each display size. There was a short block of practice trials for both the preview and the conjunction conditions prior to the main experiment, with 1,000-msec durations for extrafixation and preview. The participants were instructed to try and remain fixated through a trial

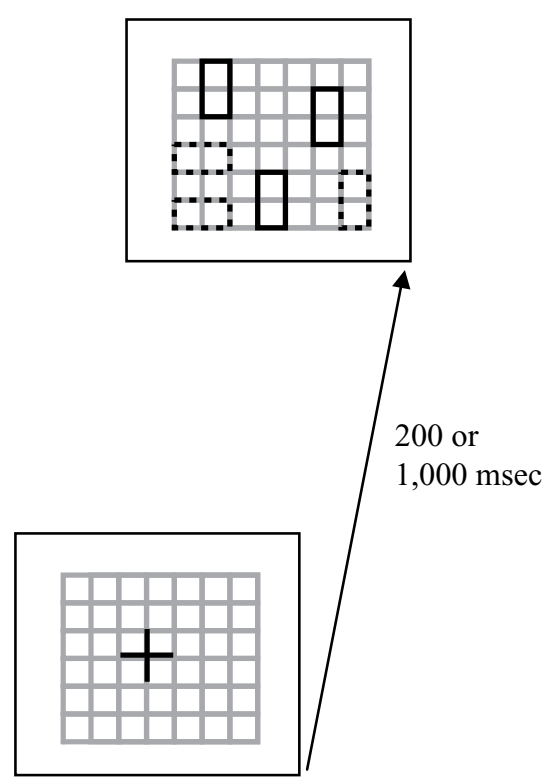

Full Set

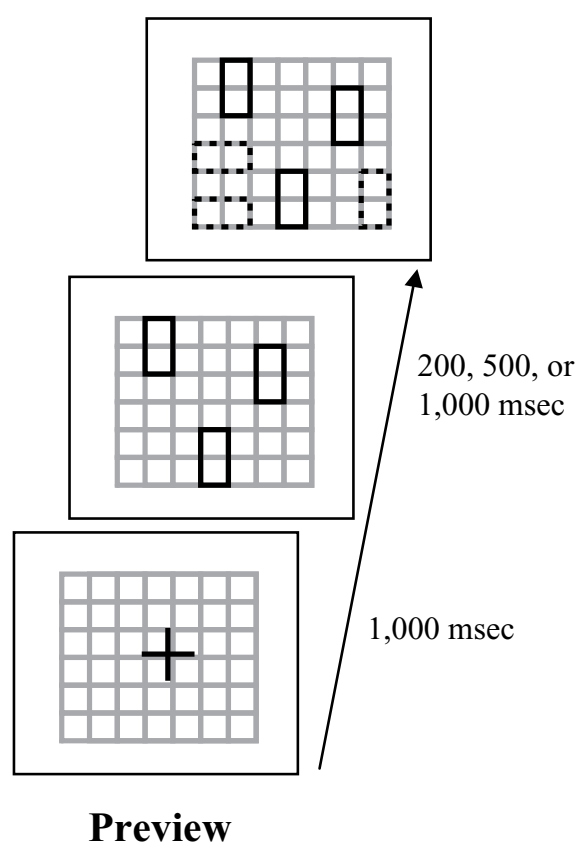

Preview

Figure 1. Example displays from Experiment 1 (color-form stimuli). Unbroken line $=$ green; broken line $=$ red. The grid (shown here in gray) was blue, and the background screen was black. The fixation cross was white. A target-present trial is shown (red vertical). Note that in the actual displays used, the size of the background grid was $22 \times 22$ squares, and the stimuli used occupied an area of $1 \times 3$ of the background squares. For ease of illustration, we show a grid of just $7 \times 6$ squares and search stimuli $1 \times 2$ squares in area. 
and to respond as soon as they detected a red vertical target. They responded by making a mouse click: the right button for target present and the left for target absent. After the response, there was a 1,000msec intertrial interval and then the next trial. Example displays are shown in Figure 1.

\section{Results}

The mean correct RTs are shown in Figure 2, and the mean percentages of errors in Table 1. Descriptive statistics for the RT search functions are presented in Table 2. The error rates were low, and there were no indications of any speed-error trade-offs. The error data were, therefore, not analyzed further. The RT data were analyzed in two ways. First, the preview and the conjunction conditions were compared in a single ANOVA with condition (preview or conjunction), duration (200 or $1,000 \mathrm{msec})$, target presence (present or absent), and display size (6 or 14 items in the final display) as factors. Second, the effects of preview duration on the preview condition alone were assessed in a three-way ANOVA with duration (200, 500, or $1,000 \mathrm{msec}$ ), target presence (present or absent), and display size (6 or 14) as factors.

Preview versus full set. All the main effects were reliable: condition $[F(1,12)=13.68, p<.01]$, time $[F(1,12)=35.48, p<.001]$, target presence $[F(1,12)=$ $42.64, p<.001]$, and display size $[F(1,12)=51.05, p<$ $.001]$. There were two-way interactions between condition and time $[F(1,12)=13.27, p<.01]$, condition and target presence $[F(1,12)=12.57, p<.01]$, condition and display
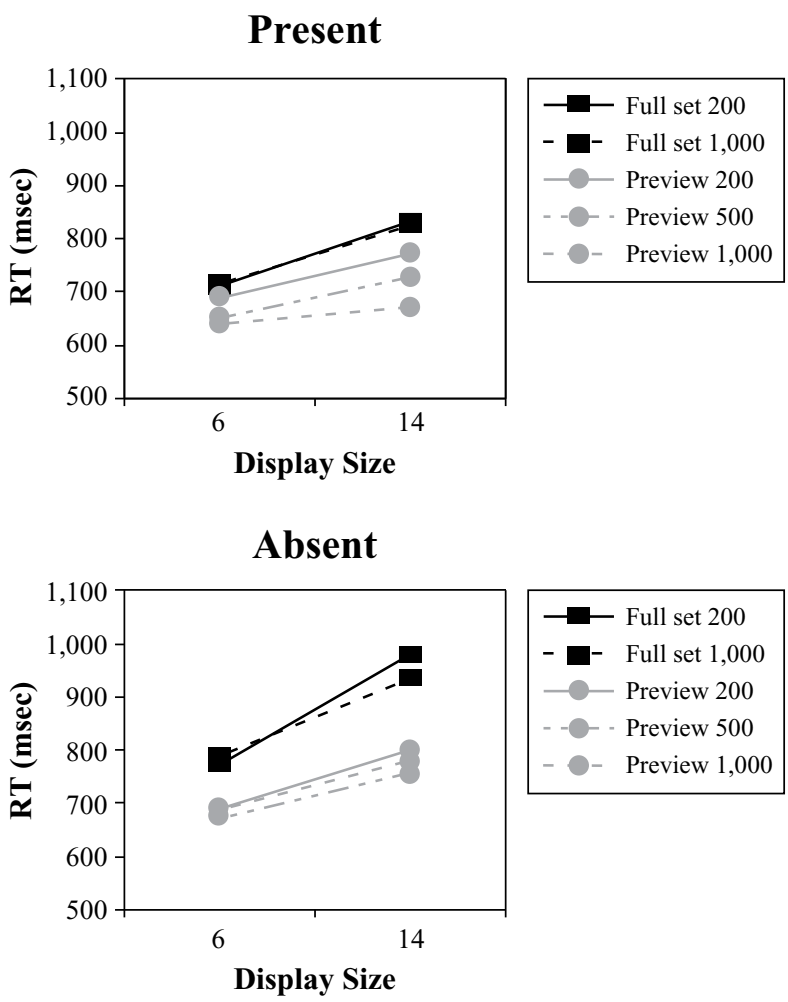

Figure 2. The mean correct response times (RTs, in milliseconds) in Experiment 1 (color-form search).
Table 1

Mean Error Rates in the Search Conditions in Experiment 1 (Color-Form Conjunctions)

\begin{tabular}{lccccc}
\hline \multirow{3}{*}{ Condition } & & \multicolumn{4}{c}{ Display Size } \\
\cline { 3 - 6 } & $\begin{array}{r}\text { Duration } \\
(\mathrm{msec})\end{array}$ & \multicolumn{2}{c}{ Target Present } & \multicolumn{2}{c}{ Target Absent } \\
\cline { 3 - 6 } \cline { 5 - 6 } Full set & 200 & .05 & .10 & .08 & .14 \\
& 1,000 & .07 & .07 & .05 & .16 \\
Preview & 200 & .02 & .05 & .05 & .10 \\
& 500 & .05 & .05 & .06 & .08 \\
& 1,000 & .03 & .04 & .05 & .06 \\
\hline
\end{tabular}

size $[F(1,12)=16.62, p<.01]$, and target presence and display size $[F(1,12)=7.06, p<.025]$. There was one reliable three-way interaction between condition, time, and display size $[F(1,12)=4.99, p<.05]$. Preview search was more efficient than that in the full-set condition, search on target-present trials was more efficient than that on targetabsent trials, and the search advantage for preview over fullset search increased at the longer preview duration. This held across both present and absent trials.

Effects of duration on preview search. To examine the effects of the duration of the first display on preview search in more detail, we compared performance in the preview condition across the three durations in the study $(200,500$, and $1,000 \mathrm{msec})$. There were reliable main effects of duration $[F(2,24)=25.16, p<.001]$, target presence $[F(1,12)=15.13, p<.01]$, and display size $[F(1,12)=38.34, p<.001]$. There was one interaction, between duration and display size $[F(2,24)=5.06, p<$ $.05]$. The effects of the display size decreased as the preview duration increased (see Figure 2).

A similar analysis on the full-set data failed to show any effect of fixation duration on performance (200 vs. $1,000 \mathrm{msec} ; F<1$ ).

\section{Discussion}

There are two main findings to note. The first is that we found a preview benefit for search, relative to a full-set baseline condition, even when both the old and the new shapes were not defined by luminance onsets but only by their colors, relative to the background grid that they appeared on, and even when luminance noise was added to the displays. This replicates the result reported by Humphreys, Kyllinsbæk, et al. (2004). The second is that in the preview condition, search efficiency improved as the duration of the preview increased. Similar improvements in search efficiency were not observed with the full-set baseline, even though the grid was in the field for the same duration then as in the preview and any effects of attention capture by the luminance noise in the grid should have been equated. This replicates prior studies in which preview search has been examined with nonisoluminant displays (Humphreys, Kyllinsbæk, et al., 2004; Watson \& Humphreys, 1997). The new result here is that we replicated the time course even when the stimuli were defined by color, rather than by luminance. The data suggest that the long time course of the effect is not due to attention's 
Table 2

Slopes (Milliseconds/Item) for the Search Conditions in Experiment 1 (Color-Form Conjunctions)

\begin{tabular}{ccr}
\hline Condition & Target & Slope \\
\hline Full set & & \\
200-msec fixation & Present & 15.25 \\
& Absent & 25.75 \\
$1,000-\mathrm{msec}$ fixation & Present & 14.00 \\
& Absent & 19.00 \\
Preview & & \\
$200 \mathrm{msec}$ & Present & 10.25 \\
& Absent & 14.00 \\
$500 \mathrm{msec}$ & Present & 9.50 \\
& Absent & 11.00 \\
$1,000 \mathrm{msec}$ & Present & 4.00 \\
& Absent & 10.00 \\
\hline
\end{tabular}

being captured when old items have sudden luminance onsets, as was proposed by Donk and Verburg (2004), since if there were any effects of onsets here, they should be equal in the preview and the baseline conditions. The effect here was also unlikely to be due to the participants' developing a better temporal expectancy of when search displays would appear as the preview duration increased, since we found no effect of the fixation interval in the full-set baseline. Indeed, on the basis of a temporal expectancy, we might expect performance to worsen as the preview duration increased, if it then became more difficult to predict the time when the search display would appear. These data, however, are consistent with the proposal that the relatively long time course of the preview effect is due to participants' having to encode a representation of the old items, which is then filtered out to prioritize search to the new stimuli.

In Experiment 2, we examined whether the duration effects in Experiment 1 reflected our use of color-segmented stimuli in the search displays (old items were green, new search stimuli red). There is evidence for color carryover effects in preview search, where targets are difficult to detect if they carry the color feature of old distractors, suggesting that the color values of old items are inhibited (Braithwaite \& Humphreys, 2003; Olivers \& Humphreys, 2003; see also Agter \& Donk, 2005, for evidence from a probe detection task). It could be that, with colorsegmented displays, participants suppress the color associated with the old items in order to optimize search for the new items (e.g., by inhibiting feature maps corresponding to the color of the distractors; cf. Treisman \& Sato, 1990) and that this suppression effect takes time. Search becomes maximally efficient only once this color suppression has taken place. To rule out this account of the duration effects, we used a form conjunction search task in Experiment 2.

\section{EXPERIMENT 2 \\ Time Course of the Preview Effect With Form Conjunctions}

\section{Method}

Unless otherwise mentioned, the method was the same as that in Experiment 1. The primary change to the experiment was that here, we had the participants search for an inverted $\mathrm{T}$ target among upright Ts and Ts rotated $90^{\circ}$ to the right. The individual T stimuli occupied three squares vertically and three squares horizontally on the grid (maximum contour lengths, $1.27^{\circ} \times 1.27^{\circ}$ ). The Ts were always drawn in green, replacing the blue contours of the background grid. As in Experiment 1, each participant first underwent a flicker fusion procedure in which the blue and the green values were set to be isoluminant with each other, relative to a gray background, for the mean and the extreme $( \pm 12 \%)$ luminance variations used in the experiment (for luminance noise). The display sizes were again 6 and 14 in the full-set baseline $(3+3$ and $7+7$ items in preview search). There were two preview durations (200 and $1,000 \mathrm{msec})$, matched by two fixation durations in the full-set baseline (200 and $1,000 \mathrm{msec}$ ). Display size was randomized with each search condition, and the different search conditions (preview and full set $\times$ 2 durations) were blocked. There were 10 participants, 6 of them female, between 18 and 26 years of age, all with either normal or corrected-to-normal vision. The order of the blocks was randomized across participants. Example displays are shown in Figure 3.

\section{Results}

The mean correct RTs (in milliseconds) are presented in Figure 4. Table 3 gives the mean error rates, and Table 4 the summary descriptive statistics for the search functions. The error rates were low, and there was no sign of a speedaccuracy trade-off. These data were not analyzed further.

The RT data were analyzed in a four-factor repeated measures ANOVA with the factors being condition (preview or full-set search), target presence (present or absent), duration ( 200 or $1,000 \mathrm{msec}$ ), and display size ( 6 or 14 items). There were significant main effects of condition, target presence, duration, and display size $[F(1,9)=$ $14.57,61.97,12.98$, and 474.22, respectively; all $p$ s $<$ $.001]$. There were reliable two-way interactions between condition and target presence $[F(1,9)=8.28, p<.025]$, condition and display size $[F(1,9)=6.73, p<.05]$, and target presence and display size $[F(1,9)=66.44, p<$ $.001]$. The three-way interaction between condition, time, and display size was also reliable $[F(1,9)=10.24, p<$ $.025]$. There were no other interactions. Preview search was more efficient than search in the full-set baseline, the change in search efficiency was greater on targetabsent than on target-present trials, and target-absent trials showed a greater effect of display size. The three-way interaction arose because the search advantage for the preview condition, relative to the full-set baseline, increased at the longer preview duration. This held across both present and absent trials.

\section{Discussion}

The pattern of the results was very similar to that found in Experiment 1, even though search here was more difficult than that for the color-form conjunctions used earlier. As in Experiment 1, we demonstrated a preview effect with stimuli defined by their color, rather than by their luminance. In Experiment 2, the preview effect occurred with form conjunctions, rather than with color-form conjunctions, ruling out the possibility that the preview effect was due to color inhibition of the old distractors (cf. Agter \& Donk, 2005; Braithwaite \& Humphreys, 2003). In addition, there was a positive effect of time on the preview benefit: The search advantage increased at the longer pre- 


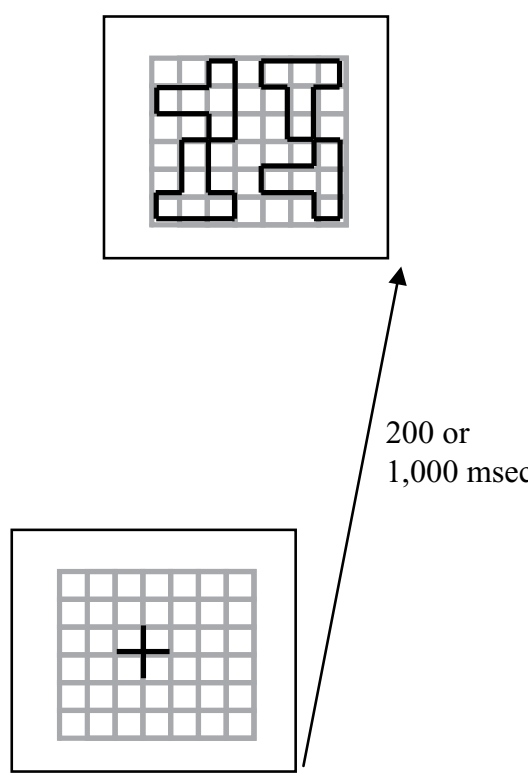

Full Set

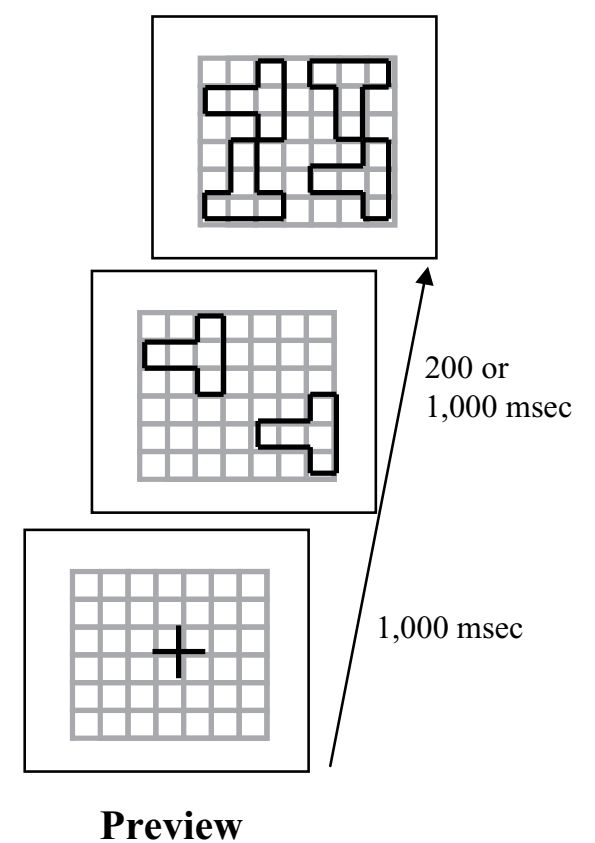

Preview

Figure 3. Example displays from Experiment 2 (form conjunctions). Unbroken line = green; background grid (shown in gray) = blue; background screen (shown in white = black). Note that in the actual displays used, the size of the background grid was $22 \times 22$ squares, and the stimuli used occupied an area of $1 \times 3$ squares horizontally by $1 \times 3$ squares vertically. For ease of illustration, we show a grid of just $7 \times 6$ squares and a small number of preview and search stimuli. Also, in the experiment, there was always a gap between neighboring shapes.

view duration. As before, there was a minimal effect of fixation duration on the full-set baseline, countering any argument that the time course of the preview benefit was due to a temporal expectancy for the new search display or to the capturing of attention by onsets in the initial display. The earlier results were not confined to displays in which participants may suppress the color of the old items in order to prioritize new stimuli with a different color.

\section{GENERAL DISCUSSION}

These data indicate the following.

1. A preview benefit can be established with displays in which the new and old items are defined by their color, rather than by luminance. This occurs both when the new and the old items have different colors (Experiment 1; see also Humphreys, Jung-Stalmann, \& Olivers, 2004) and when they have the same color (Experiment 2). Defining a target in terms of new luminance onsets is not necessary to create a preview benefit.

2. The preview benefit with color-defined items has a relatively long time course, so that the preview advantage is increased with previews of $1,000 \mathrm{msec}$, in comparison with shorter previews (e.g., $200 \mathrm{msec}$ ). There are no effects of giving a similar temporal cue to the luminance onset of the search display in a full-set baseline condition, suggesting that the effects of time on preview search are not caused by a temporal expectancy as to the luminance onset of the search display or by luminance capture by the initial display.

The data are consistent with the notion that in order to optimize search under preview conditions, participants encode a representation of the old items and then filter this out from the subsequent search process when new items appear (Watson \& Humphreys, 1997; Watson et al., 2003). This filtering process may involve suppression of both the locations of the old items (Humphreys, Jung-Stalmann, \& Olivers, 2004) and their color (Agter \& Donk, 2005; Braithwaite \& Humphreys, 2003). According to this view, the time course of preview search is generated by the time required for these encoding and suppression processes, neither of which is instantaneous. The long time course is not predicted by either the luminance onset capture account of preview search (Donk \& Theeuwes, 2001) or the temporal grouping account (Jiang et al., 2002), given that visual events can be segmented within a much shorter time scale (Rauschenberger, 2003; Yantis \& Gibson, 1994). Our finding of a preview benefit even when there are no new luminance onsets that consistently define the search items also directly contradicts the luminance onset capture proposal.

Why have we been able to establish a preview benefit when stimuli are not defined by luminance onsets, when Donk and Theeuwes (2001) failed to do this (see also Belopolsky, Theeuwes, \& Kramer, 2005; Braithwaite, Hulleman, Watson, \& Humphreys, 2006; Braithwaite et al., 


\section{Present}
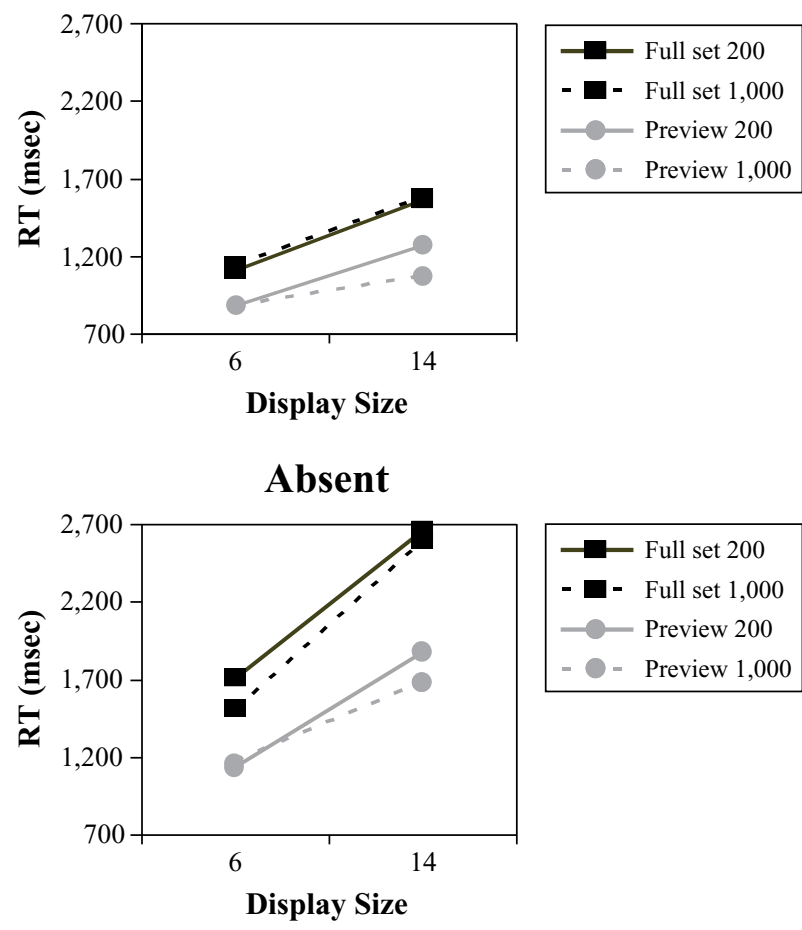

Figure 4. The mean correct response times (RTs, in milliseconds) in Experiment 2 (form conjunctions).

2005)? There are several procedural differences between our studies that may be important. One is that we measured preview search against a full-set baseline condition; this has not always been done (Donk \& Theeuwes, 2001). This contrast between the preview and the full-set condition provides an assessment of whether there is any facilitation from preview search, even if there is some impact of the old items on performance. A second difference between our procedure and that of others is that we presented shapes by changing the colors of the elements in a background grid in displays in which there was also random luminance noise. The random changes in luminance meant that at each point in time, each line segment differed in luminance from its local surround, even though these local luminance differences contributed nothing to the overall definition of each object (since the background grid itself contained similar luminance changes). These local luminance changes, coupled with the color information from the shapes, meant that the participants always had accurate information about the location of the shapes. In contrast, when the shapes are isoluminant with the screen (Belopolsky et al., 2005; Braithwaite et al., 2006; Braithwaite et al., 2005; Donk \& Theeuwes, 2001), information about the locations of individual items may be relatively impoverished (see Livingstone \& Hubel, 1987). Since any filtering of the old items may involve coding and rejecting their positions, the filtering process should consequently suffer. Braithwaite et al. (2006) further proposed that location coding of stimuli isoluminant with the screen can take place but that it is slow, relative to when shapes differ in luminance, relative to the screen. Consistent with this, they established a preview benefit when both old and new items were isoluminant with the screen, but only when the duration of the old items was increased to $3,000 \mathrm{msec}$, and they failed to find a benefit when a preview duration of 1,000 msec was employed (a duration that produces a robust benefit with nonisoluminant stimuli; Humphreys, Kyllinsbæk, et al., 2004; Watson \& Humphreys, 1997). The benefit did not come about through sensory adaptation in the long preview condition, since any advantage was eliminated when the participants performed a secondary task during the preview. Sensory adaptation should have been equated in this dual-task condition, although the secondary task would disrupt representation and inhibition of the old items (see also Humphreys et al., 2002; Watson \& Humphreys, 1997). Braithwaite et al. (2006) argued that an extended preview was required in their case because of the slow assimilation of location information when the stimuli were isoluminant with the screen.

Now, if defining old items by luminance onsets is not necessary to generate a time course for the preview effect, might the time course be due to the need to disengage from new objects (as opposed to luminance onsets) in the preview set? There is evidence that color changes defining new objects can automatically attract attention (Cole, Kentridge, \& Heywood, 2005; Snowden, 2002), and it may be, therefore, that the participants attended to the old items that were defined by the color changes here and that it then took time to disengage attention. In some respects, this account overlaps with the account of preview search in terms of visual marking, in which it is suggested that participants first attend to the old items and then filter them out from subsequent search (Watson et al., 2003). Two differences with the marking account, though, are that according to the marking account, (1) old items are suppressed and (2) the effect depends on the intentional set of the observer. Humphreys, Jung-Stalmann, and Olivers (2004) reported evidence consistent with both of the last proposals. They used a probe dot procedure to measure attentional allocation and found that participants did initially attend to the old items but that, later on, attention was less likely to be allocated to old items than even to neutral (unoccupied) locations in displays. Furthermore, there was variation in probe dot detection, as a function of whether the dots fell on old items or neutral locations, only when the primary task was to search the new displays

Table 3

Mean Error Rates in the Search Conditions in Experiment 2 (Form Conjunctions)

\begin{tabular}{lccccc}
\hline & & \multicolumn{4}{c}{ Display Size } \\
\cline { 3 - 6 } Condition & $\begin{array}{c}\text { Duration } \\
(\mathrm{msec})\end{array}$ & \multicolumn{2}{c}{ Target Present } & & \multicolumn{2}{c}{ Target Absent } \\
\cline { 3 - 7 } \cline { 4 - 6 } Full set & 200 & .06 & .09 & .07 & .13 \\
& 1,000 & .04 & .12 & .08 & .14 \\
Preview & 200 & .06 & .09 & .07 & .09 \\
& 1,000 & .04 & .05 & .05 & .08 \\
\hline
\end{tabular}


Table 4

Slopes (Milliseconds/Item) for the Search Conditions in Experiment 2 (Form Conjunctions)

\begin{tabular}{ccr}
\hline Condition & Target & Slope \\
\hline Full set & & \\
200-msec fixation & Present & 57.00 \\
& Absent & 119.50 \\
$1,000-\mathrm{msec}$ fixation & Present & 55.25 \\
& Absent & 135.00 \\
Preview & & \\
$200 \mathrm{msec}$ & Present & 49.00 \\
$1,000 \mathrm{msec}$ & Absent & 111.00 \\
& Present & 24.25 \\
& Absent & 89.00 \\
\hline
\end{tabular}

for a target; there were no effects of probe location when the main task was probe detection. The last result goes against the idea of automatic capture of attention by the old objects. Finally, on a pure disengagement account, it is difficult to see why the time course appears to be so long and why it is apparently even more prolonged with stimuli that are fully isoluminant with their background (but still color defined as new objects; Braithwaite et al., 2006). Indeed, other studies have shown that the allocation of attention from one stimulus to another, new object can take place well within $200 \mathrm{msec}$ or so (Rauschenberger, 2003; Yantis \& Gibson, 1994).

In sum, both our data and those in Braithwaite et al. (2006) and Humphreys, Jung-Stalmann, and Olivers (2004) indicate that new items do not have to be defined by luminance onsets to be prioritized in preview search, although the presentation conditions are important in determining whether a preview benefit emerges with items defined purely by their color. Furthermore, the present results indicate that even when the stimuli are not defined by luminance onsets, preview search is optimized over time.

\section{REFERENCES}

Agter, F., \& Donk, M. (2005). Prioritized selection in visual search through onset capture and color inhibition: Evidence from a probe-dot detection task. Journal of Experimental Psychology: Human Perception \& Performance, 31, 722-730.

Belopolsky, A. V., Theeuwes, J., \& Kramer, A. F. (2005). Prioritization by transients in visual search. Psychonomic Bulletin \& Review, 12, 93-99.

Braithwaite, J. J., Hulleman, J., Watson, D. G., \& Humphreys, G. W. (2006). Is it impossible to inhibit isoluminant items, or does it simply take longer? Evidence from preview search. Perception \& Psychophysics, 68, 290-300.

Braithwaite, J. J., \& Humphreys, G. W. (2003). Inhibition and anticipation in visual search: Evidence from effects of color foreknowledge on preview search. Perception \& Psychophysics, 65, 213-237.
Braithwaite, J. J., Humphreys, G. W., Watson, D. G., \& Hulleman, J. (2005). Revisiting preview search at isoluminance: New onsets are not necessary for the preview advantage. Perception \& Psychophysics, 67, 1214-1228.

Cepeda, N. J., Cave, K. R., Bichot, N. P., \& Kim, M.-S. (1998). Spatial selection via feature-driven inhibition of distractor locations. Perception \& Psychophysics, 60, 727-746.

Cole, G. C., Kentridge, R. W., \& Heywood, C. A. (2005). Object onset and parvocellular guidance of attentional allocation. Psychological Science, 16, 270-274.

Donk, M., \& Theeuwes, J. (2001). Visual marking beside the mark: Prioritizing selection by abrupt onsets. Perception \& Psychophysics, 63, 891-900.

Donk, M., \& Verburg, R. C. (2004). Prioritizing new elements with a brief preview period: Evidence against visual marking. Psychonomic Bulletin \& Review, 11, 282-288.

Humphreys, G. W., Jung Stalmann, B., \& Olivers, C. (2004). An analysis of the time course of attention in preview search. Perception \& Psychophysics, 66, 713-730.

Humphreys, G. W., KyllinsbæK, S., Watson, D. G., Olivers, C. N. L., LaW, I., \& Paulson, O. (2004). Parieto-occipital areas involved in efficient filtering in search: A time course analysis of visual marking using behavioural and functional imaging procedures. Quarterly Journal of Experimental Psychology, 57A, 610-635.

Humphreys, G. W., Quinlan, P. T., \& RidDOCH, M. J. (1989). Grouping effects in visual search: Effects with single- and combined-feature targets. Journal of Experimental Psychology: General, 118, 258-279.

Humphreys, G. W., Watson, D. G., \& Joliceur, P. (2002). Fractionating visual marking: Dual-task decomposition of the marking state by timing and modality. Journal of Experimental Psychology: Human Perception \& Performance, 28, 640-660.

Jiang, Y., Chun, M. M., \& Marks, L. E. (2002). Visual marking: Selective attention to asynchronous temporal groups. Journal of Experimental Psychology: Human Perception \& Performance, 28, 717-730.

Livingstone, M. S., \& Hubel, D. H. (1987). Psychophysical evidence for separate channels for the perception of form, color, movement and depth. Journal of Neuroscience, 7, 3416-3468.

Olivers, C. N. L., \& HumphreYs, G. W. (2003). Visual marking and singleton capture: Fractionating the unitary nature of visual selection. Cognitive Psychology, 47, 1-42.

RAUSCHENBERGER, R. (2003). When something old becomes something new: Spatiotemporal object continuity and attentional capture. Journal of Experimental Psychology: Human Perception \& Performance, 29, 600-615.

SNOWDEN, R. J. (2002). Visual attention to color: Parvocellular guidance of attentional resources? Psychological Science, 13, 180-184.

Treisman, A., \& Sato, S. (1990). Conjunction search revisited. Journal of Experimental Psychology: Human Perception \& Performance, 16, 459-478.

Watson, D. G., \& Humphreys, G. W. (1997). Visual marking: Prioritising selection for new objects by top-down attentional inhibition. Psychological Review, 104, 90-122.

Watson, D. G., Humphreys, G. W., \& Olivers, C. N. L. (2003). Visual marking: Using time in visual selection. Trends in Cognitive Sciences, 7, 180-186.

Yantis, S., \& Gibson, B. (1994). Object continuity in apparent motion and attention. Canadian Journal of Experimental Psychology, 48, 182-204.

(Manuscript received May 24, 2005; revision accepted for publication January 30, 2006.) 